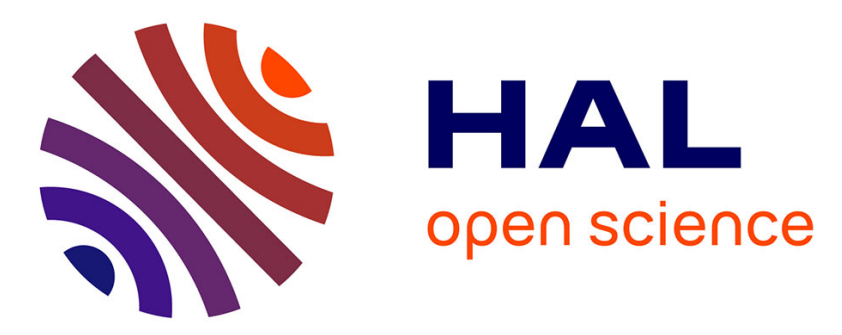

\title{
Assessment of Ageing in the Insulation of HVDC Model Cables under Thermo-electric Stress
}

\author{
J. Cenes, G. Teyssedre, Séverine Le Roy, Laurent Berquez, P. Hondaa, C. \\ Moreau, V. Eriksson, W. Loyens
}

\section{- To cite this version:}

J. Cenes, G. Teyssedre, Séverine Le Roy, Laurent Berquez, P. Hondaa, et al.. Assessment of Ageing in the Insulation of HVDC Model Cables under Thermo-electric Stress. 2nd International Conference on Dielectrics (ICD 2018), Jul 2018, Budapest, Hungary. 10.1109/ICD.2018.8514774 • hal-02396207

\section{HAL Id: hal-02396207 https://hal.science/hal-02396207}

Submitted on 25 Nov 2020

HAL is a multi-disciplinary open access archive for the deposit and dissemination of scientific research documents, whether they are published or not. The documents may come from teaching and research institutions in France or abroad, or from public or private research centers.
L'archive ouverte pluridisciplinaire HAL, est destinée au dépôt et à la diffusion de documents scientifiques de niveau recherche, publiés ou non, émanant des établissements d'enseignement et de recherche français ou étrangers, des laboratoires publics ou privés. 


\section{Assessment of Ageing in the Insulation of HVDC Model Cables under Thermo-electric Stress}

\author{
J. Cenes*, G. Teyssedre, S. Le Roy, L. Berquez \\ Laplace, CNRS and University of Toulouse \\ Toulouse, France \\ *julien.cenes@laplace.univ-tlse.fr
}

\author{
C. Moreau \\ EDF R\&D, \\ Moret-sur-Loing, France
}

\author{
P. Hondaâ \\ RTE, \\ Paris - La Défense, France \\ V. Eriksson, W. Loyens \\ Borealis AB, \\ Stenungsund, Sweden
}

\begin{abstract}
The assessment of insulating materials regarding space charge features is one important aspect of HVDC cable development. Whereas most of space charge characterization is achieved under relatively short stressing time, it is important to understand if there is an evolution of materials behavior during long time under stresses, including service stresses such as combination of electrical and thermal stresses along with polarity reversal. Our purpose in this communication is to present the implementation of long term ageing tests on crosslinked polyethylene materials in such a way that relevant and valuable information can be gained as a function of stressing time. The designed stress cycle on model cables encompasses maximum fields up to $90 \mathrm{kV} / \mathrm{mm}$ at the inner semiconductor and temperature up to $100^{\circ} \mathrm{C}$ with repetitive grounding or polarity reversal. The stressing time is up to 18 months. The electrical and physicochemical characterizations techniques as well as the first ageing results are presented.
\end{abstract}

Keywords-XLPE; HVDC; Ageing; Space charge; cables; Conductivity; Polarity reversal

\section{INTRODUCTION}

One important property in the development of polymerinsulated cables for HVDC energy transmission is space charge build-up in the material that can potentially induce substantial field redistribution into the insulation and alter long-term performance or reliability [1]. Accordingly, one of the main properties probed when developing insulating materials and related processes is the propensity of materials to accumulate charges. However, most of published space charge studies on insulating materials involve relatively short stressing times. The approach does not necessarily account for the possible evolution of material properties during long time stressing, especially if thermal and electrical stresses are combined. Besides space charge accumulation, it is also important that the electrical conductivity of the material remains at a low and controlled level during service. In addition, the polymer structure should also remain stable in service conditions. The purpose of this paper is to present the long term ageing tests performed on crosslinked polyethylene (XLPE) materials in such a way that relevant and valuable information can be gained as a function of time and repetitive variations of the DC stress.

\section{SAMPLES AND PROTOCOLS}

The samples used for ageing are model cables (Fig. 1), produced by triple extrusion using crosslinked polyethylene insulation and semiconductive shield using grades developed for the currently most demanding commercial HVDC applications. The main advantage of this type of samples compared to plaques is the cylindrical geometry. Accordingly, the tests to be applied have to be adapted to this geometry. The thermal and electrical ageing conditions were designed in order to study the effect of isothermal ageing up to $100^{\circ} \mathrm{C}$, thermal gradient, and the effects of grounding and polarity reversal. Ageing is planned for up to 18 months and at electrical stresses up to $90 \mathrm{kV} / \mathrm{mm}$ at the interface between the insulation and the inner semiconductive shield. Given the geometry of the cable, when applying $90 \mathrm{kV}$ to the conductor, the field at the inner semiconductive shield is $90 \mathrm{kV} / \mathrm{mm}$, at the outer semiconductive shield $45 \mathrm{kV} / \mathrm{mm}$ and the average field $\mathrm{E}_{\mathrm{av}}$ is $60 \mathrm{kV} / \mathrm{mm}$. For each condition, electro-thermal ageing is compared to thermal ageing alone in order to distinguish the effects. As electrical characterization, space charge measurements, either on-line during ageing or off-line on aged samples, and DC conductivity are performed. Physical and chemical analyses are planned on samples taken at intermediate times in order to monitor the potential change of the properties of the XLPE during ageing.

\section{A. Ageing protocol}

After extrusion, model cables were degassed for 10 days at

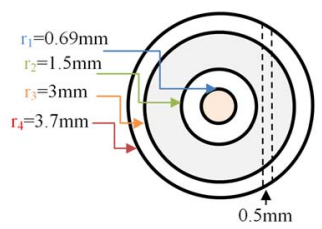

Fig. 1. Model cable geometry and sampling for physicochemical analyses. 
$70^{\circ} \mathrm{C}$ to remove XLPE crosslinking decomposition products [2]. Two ageing bench set-ups are run in parallel. In bench 1, relatively short ageing times are used, typically 42 days, in which a thermal gradient (TG) is applied to the cables and either grounding (G) or polarity inversion (IP), are applied periodically. Space charge profiles are measured periodically during the ageing. Samples are aged under different stresses with grounding or polarity reversal at $E_{a v}=60 \mathrm{kV} / \mathrm{mm}$ or 45 $\mathrm{kV} / \mathrm{mm}$. The temperature $\mathrm{T}_{\text {in }}$ at the conductor is $90^{\circ} \mathrm{C}$ or $70^{\circ} \mathrm{C}$, the corresponding calculated temperature difference between inner and outer semiconductive shields are $\Delta \mathrm{T}=5.7^{\circ} \mathrm{C}$ and $4.3^{\circ} \mathrm{C}$, respectively. Fig. 2 shows an example of polarity inversion procedure.

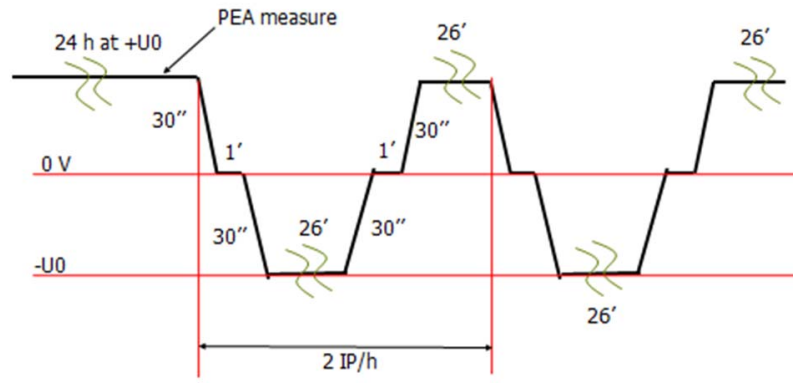

Fig. 2. Schematic of polarity inversion cycle $\left(+\mathrm{U}_{0}\right.$ during $24 \mathrm{~h}$ and 2 $\mathrm{IP} /$ hour during $24 \mathrm{~h}=48 \mathrm{IP}$ )

Fig. 3 shows the part for the PEA measurement on test bench 1 . The voltage is applied using two high voltage power supplies of inverse polarity, both connected to a high voltage switch for polarity reversal. The temperature gradient is applied using Joule effect in the cable conductor through a current transformer. Three cables are installed in parallel: $\mathrm{i} /$ cable 1 for on-line space charge measurement during electro-thermal ageing; ii/ cable 2 for sampling for offline electrical and physicochemical characterization during electro-thermal ageing; iii/ cable 3 same as cable 2 for thermal aging only.

In parallel to the ageing performed in bench 1, a cable is aged for 18 months in bench 2 at a constant average stress of $60 \mathrm{kV} / \mathrm{mm}$ and under isothermal condition $\left(\mathrm{T}=100^{\circ} \mathrm{C}\right)$ in an oven. A reference cable is also aged in parallel but only under thermal stress at $\mathrm{T}=100^{\circ} \mathrm{C}$. A sampling is made every 42 days for space charge, conductivity, and physicochemical off-line measurements.

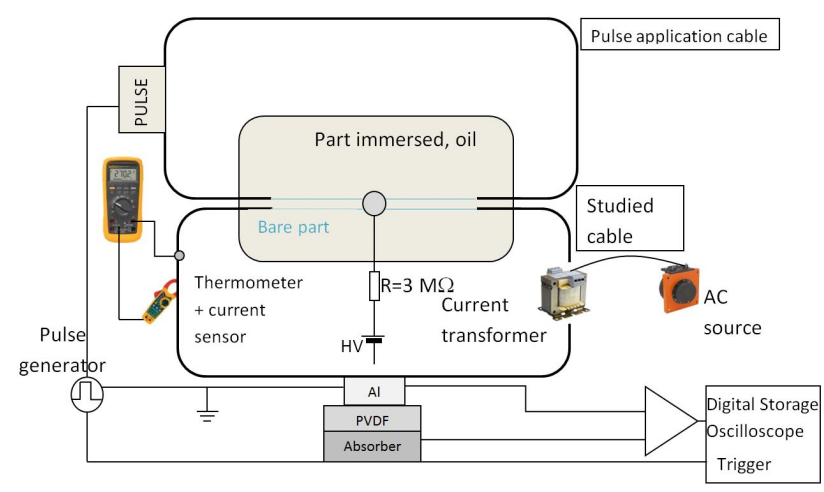

Fig. 3. Schematic of PEA test bench for space charge measurements on model cables.

\section{B. Space charge measurements}

Space charge measurements are realized by means of pulsed electro-acoustic (PEA) method. The average applied field is $60 \mathrm{kV} / \mathrm{mm}$ in the first results presented. Measurements are recorded under thermal gradient. It is also important to note that the cable 1 in the PEA test cell has a substantially lower temperature compared to the cable part outside the cell due to the fact that it acts as a thermal sink. Therefore 'online' PEA profiles for cable 1 are measured at the same electrical stress and same $\Delta \mathrm{T}=5.7^{\circ} \mathrm{C}$ but at different average temperature $\left(\mathrm{T}_{\mathrm{av}}=36^{\circ} \mathrm{C}\right)$ compared to cable $2\left(\mathrm{~T}_{\mathrm{av}}=83^{\circ} \mathrm{C}\right)$. Each space charge measurement sequence lasts for $24 \mathrm{~h}$ in which records are realized every $100 \mathrm{~s}$ under constant voltage. For off-line measurements (on samples aged in bench 2), the average field is $45 \mathrm{kV} / \mathrm{mm}$, with a temperature gradient of $4.3^{\circ} \mathrm{C}$. Each polarization and depolarization step lasts for $4 \mathrm{~h}$. The pulse is generated with a frequency of $5 \mathrm{kHz}$ and an amplitude of $1.5 \mathrm{kV}$ on a separated cable (pulse cable), cf. Fig. 3.

\section{Current measurement}

Current measurement is carried out on cable sample of $90 \mathrm{~cm}$ long. The outer semiconductive material is stripped at both ends of the cable over $30 \mathrm{~cm}$. Guard electrodes of $1 \mathrm{~cm}$ width are set close to the section on which the current is measured, which is about $30 \mathrm{~cm}$. Measurements are performed under average DC electric field from 5 to $20 \mathrm{kV} / \mathrm{mm}$ in isothermal conditions at $\mathrm{T}=70^{\circ} \mathrm{C}$ in an oven. The voltage is applied to the conductor. Current values are recorded every $2 \mathrm{~s}$ during the polarization/depolarization steps which last for $4 \mathrm{~h}$ each.

\section{Physicochemical measurement}

Besides electrical characteristics, different techniques are implemented to evaluate the physical and mechanical properties of the insulation material under aging. Dynamic Mechanical Thermal Analysis (DMTA) is used to follow the evolution of the mechanical properties of XLPE (real E', and imaginary E" moduli and damping $\tan \delta$ [3]). Specimens of dimension $L \times l \times e=50 \times 7 \times 0.5 \mathrm{~mm}^{3}$ are cut parallel to the axis of the cable (see Fig. 1) using a slicing machine. DMTA measurements are made in traction mode at a constant frequency of $1 \mathrm{~Hz}$, in the temperature range from 25 to $120^{\circ} \mathrm{C}$. Thermogravimetric analysis (TGA) and Differential Scanning Calorimetry (DSC) are used respectively to detect potential changes in the degradation kinetics and in the crystallinity degree and melting point as a function of ageing conditions (temperature $\mathrm{ramp}=10^{\circ} \mathrm{C} / \mathrm{min}$ from $25^{\circ} \mathrm{C}$ to $180^{\circ} \mathrm{C}$ ). Finally Fourier Transform Infrared Spectroscopy (FTIR) is used to evaluate the effects of aging on the macromolecular structure of the studied insulation. The main chemical modification is the formation of carbonyl groups by oxidation of the polymer [4]. The samples for FTIR measurements are the same as for DMTA. Those for TGA and DSC are prepared in the same way as for DMTA, i.e. in the form of specimens and then cut again into adequate shape.

\section{BENCHMARK}

The properties of XLPE, before ageing, on cables have been carefully determined as they are the baseline for the 
entire study. From DSC data, the degree of crystallinity is $44 \%$ and the melting temperature is $107.8^{\circ} \mathrm{C}$.

\section{A. Space charge results}

The measurement is carried out over a period of $4 \mathrm{~h}$ of polarization and $4 \mathrm{~h}$ of depolarization for each average field of 30,50 , and $60 \mathrm{kV} / \mathrm{mm}$. The charging and discharging steps at the different fields were applied in series on the same sample. The space charge patterns are shown in Fig. 4. For an average field of $30 \mathrm{kV} / \mathrm{mm}$ (Fig. 4a), charges are difficult to observe during polarization. However, positive charges are visible during short-circuit in the first half of the insulator. This indicates that these charges have been generated during polarization at the inner semiconductive shield and have moved towards the outer electrode. The absence of negative charges in the vicinity of the outer semiconductive shield is also noticeable. The density of injected charges is greater as the electric field is increased. Under $50 \mathrm{kV} / \mathrm{mm}$, the positive space charge region occupies nearly all the insulation. No negative charges are observed. The resorption of positive charges during the depolarization phase is clear in Fig. 4. For stresses of 50 and $60 \mathrm{kV} / \mathrm{mm}$, the charge amount appears higher close to the outer semiconductive shield.

Under thermal gradient, the gradient in electrical conductivity produces a field redistribution given under steady state conditions by equation $1[5]$ :

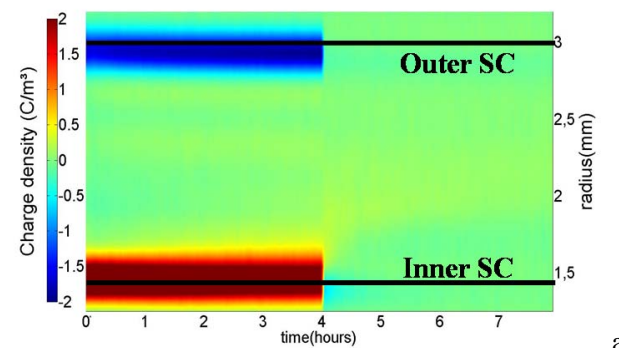

a)

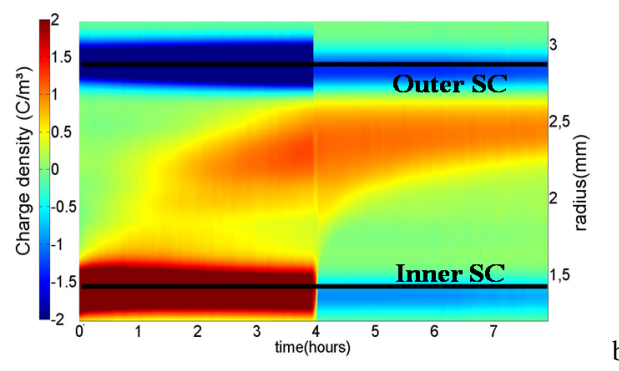

b)

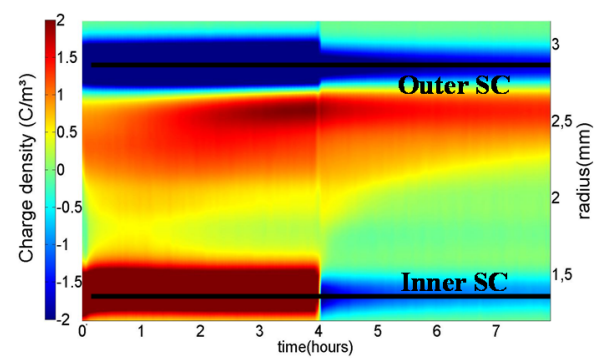

Fig. 4. Space charge mapping for a $4 \mathrm{~h} / 4 \mathrm{~h}$ polarization / depolarization protocol of the insulator under thermal gradient of $\Delta \mathrm{T}=4.3^{\circ} \mathrm{C}$ for average fields of a) $30 \mathrm{kV} / \mathrm{mm}$, b) $50 \mathrm{kV} / \mathrm{mm}$; c) $60 \mathrm{kV} / \mathrm{mm}$.

$$
E(r)=E_{c} \frac{r_{c} \sigma_{c}}{r \sigma(r)}
$$

where $E_{c}$ and $\sigma_{c}$ are the electric field and the conductivity at the reference position $r_{c}$. The corresponding 'geometrical' space charge distribution is of the form:

$$
\rho_{g}(r)=\operatorname{div}(\varepsilon \cdot E)=-E(r) \frac{\varepsilon}{\sigma(r)} \frac{\partial \sigma(r)}{d r}
$$

where $\varepsilon$ is the dielectric permittivity. For a positive voltage applied to the conductor, and supposing that $\sigma(\mathrm{r})$ decreases with $r$, the space charge is positive as is actually measured. However the accumulation of charges close to the outer semiconductive shield is not predicted by the expression.

\section{B. Experimental results on conductivity}

Fig. 5 shows experimental results of polarization current vs. time at $70^{\circ} \mathrm{C}$ for different stresses. The current has been normalized based on the current value at $70^{\circ} \mathrm{C}$ and $5 \mathrm{kV} / \mathrm{mm}$, after $4 \mathrm{~h}$ of polarization. The steady state conduction is approached after $4 \mathrm{~h}$ of charging for the highest constraints. The transient current for $5 \mathrm{kV} / \mathrm{mm}$ has a different shape presumably because of the thermal history.

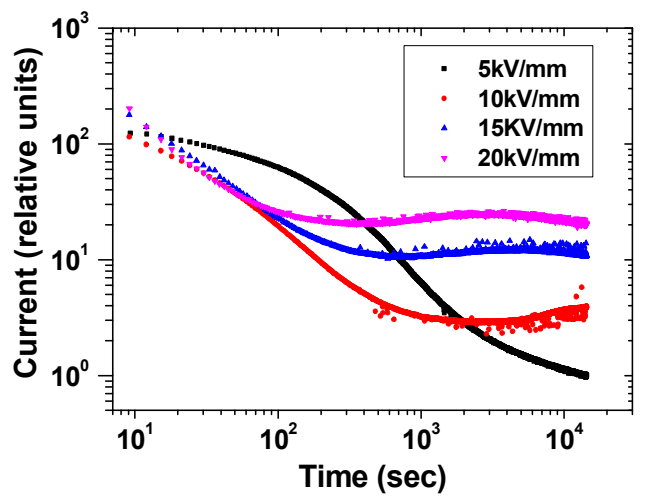

Fig. 5. Polarization currents under different stresses at $70^{\circ} \mathrm{C}$.

The conductivity was estimated from current taken after $4 \mathrm{~h}$ of polarization. At $70^{\circ} \mathrm{C}$, the $\mathrm{DC}$ conductivity is relatively low and increases substantially with the field. So the field in the cable will be redistributed according to the temperature and field dependencies of the conductivity, besides potential space charge accumulation.

TABLE I. RELATIVE CONDUCTIVITY AS FONCTION OF THE AVERAGE FIELD AND TEMPERATURE

\begin{tabular}{|c|c|c|c|c|}
\hline Field (kV/mm) & $\mathbf{5}$ & $\mathbf{1 0}$ & $\mathbf{1 5}$ & $\mathbf{2 0}$ \\
\hline & \multicolumn{4}{|c|}{ Conductivity (relative units) } \\
\hline $\mathrm{T}=25^{\circ} \mathrm{C}$ & 0.122 & 0.139 & 0.134 & 0.135 \\
\hline $\mathrm{T}=70^{\circ} \mathrm{C}$ & 1 & 2.08 & 3.83 & 5.43 \\
\hline \multicolumn{5}{|c|}{${ }^{\mathrm{a}}$ Normalized based on conductivity value at $70^{\circ} \mathrm{C}$ and $5 \mathrm{kV} / \mathrm{mm}}$. \\
\hline
\end{tabular}

\section{AgEING RESULTS}

\section{A. Space charge results after ageing}

These results arise from the test bench 2, where the ageing is performed under isothermal conditions $\left(100^{\circ} \mathrm{C}\right.$, and an average field of $60 \mathrm{kV} / \mathrm{mm}$ ). During the space charge characterization, i.e. $4 \mathrm{~h}$ polarization at $45 \mathrm{kV} / \mathrm{mm}$ and $70^{\circ} \mathrm{C}$, 

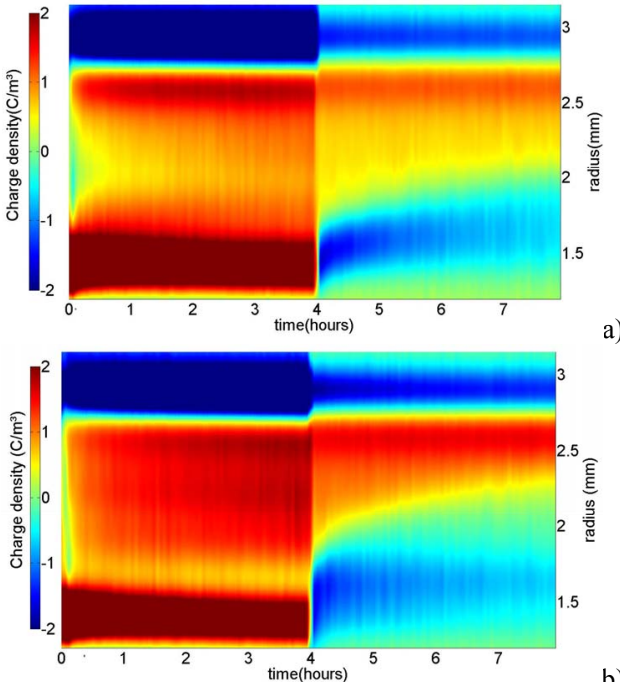

b)
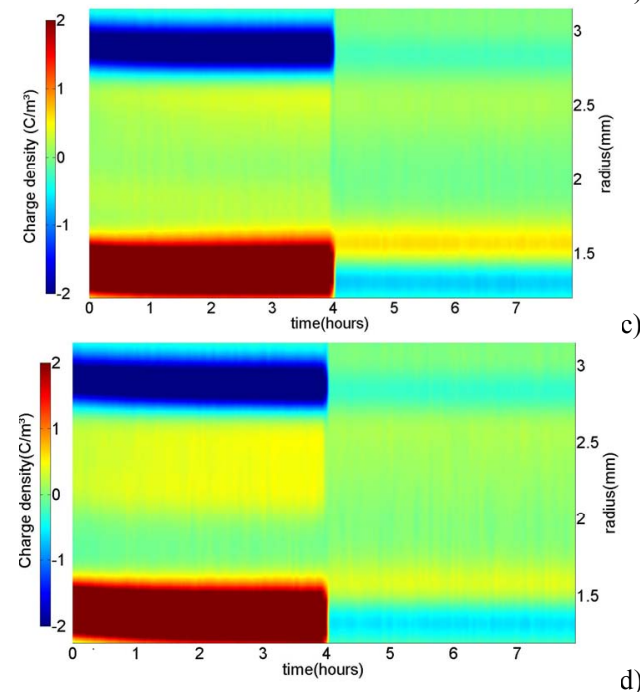

d)

Fig. 6. Mapping of the charge density for the thermal cable $\left(100^{\circ} \mathrm{C}\right)$ for a) 42 days, b) 84 days, and for the electro-thermal cable $\left(100^{\circ} \mathrm{C}, 60\right.$ $\mathrm{kV} / \mathrm{mm}$ ) during c) 42 days, d) 84 days.

we observed in Fig. 6a and 6b, for the thermal cable, positive charges in the bulk. The charge density intensifies near the outer semiconductive shield with ageing time. For the electrothermal cable (Fig. 6c and 6d), a small positive heterocharge is detected at the vicinity of the outer SC. This density seems to increase with ageing time, but remains very low compared to the thermal cable.

\section{B. Experimental results on conductivity after ageing}

Fig. 7 shows the relative conductivity as a function of applied average field for different ageing times with a thermal gradient or under isothermal conditions. The relative conductivity is calculated based on the conductivity of the benchmark measured at $70^{\circ} \mathrm{C}$ and $5 \mathrm{kV} / \mathrm{mm}$. Data from the benchmark and obtained for sample aged under thermal stress alone are added for comparison. We observe that the trend for the conductivity is a decrease with ageing time for the 4 cases tested. The effect is more important with the thermal stress than with electro-thermal stresses. Cables aged under thermal stress alone, being under thermal gradient or isothermal conditions, have a conductivity of a decade higher compared to the ones aged under electrothermal stress. So the material acts as if the electric field was driving charges outside the sample during stressing. It would be consistent with the relative decrease in charge amount obtained in Fig. 6 compared to Fig 4c (though the temperature was not $90^{\circ} \mathrm{C}$ in space charge data).
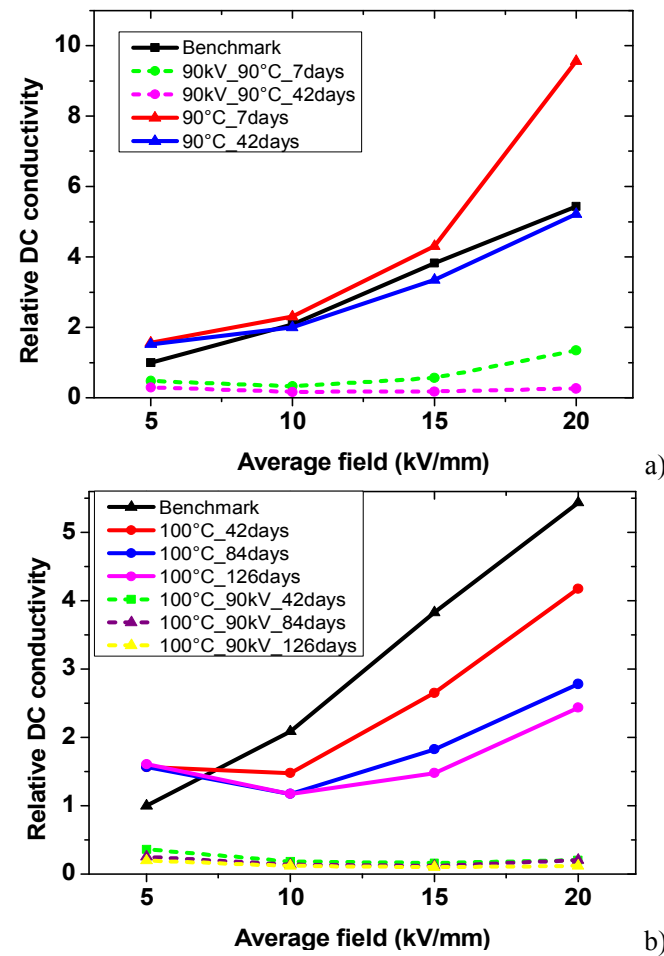

Fig. 7. Relative conductivity vs. applied average field for different stresses and ageing times: a) ageing with thermal gradient; b) ageing in isothermal conditions.

\section{CONCLUSION}

The methodology settled for evaluating thermoelectric ageing in model cables has been described. On-line space charge measurements are achieved during ageing but not in conditions of nominal thermal stress. The implemented means provide information on space charge behavior, conductivity and physicochemical parameters. Preliminary results with stressing under relatively severe conditions in terms of field indicate a substantial decrease in conductivity under thermoelectric stress compared to thermal stresses. The space charge patterns are different considering thermal and electro thermal stress. In the forthcoming steps the impact of polarity inversion ageing on space charge will be investigated comparatively to grounding ageing.

\section{REFERENCES}

[1] G.C. Montanari, IEEE Trans. Dielectr. Electr. Insul., vol. 18, pp. 339364, 2011.

[2] T. Andrew, R.N. Hampton, A. Smedberg, D.A. Wald, V. Waschk and W. Weissenberg, IEEE Electr. Insul. Mag., vol. 22, pp. 5-16, 2006.

[3] J.L. Parpal, C. Guddemi and L. Lamarre; Proc. IEEE. Internat. Symp. Electr. Insul. (ISEI), pp. 171-174, 1996.

[4] J.V. Gulmine and L. Akcelrud, Polymer Testing, vol. 25, pp. 932-942, 2006.

[5] N. Adi, T.T.N. Vu, G. Teyssèdre and N. Sinisuka, Technologies, vol. 5, 46 (10p), 2017. 